\title{
Unilateral Corneal Ectasia after Bilateral LASIK: The Thick Flap Counts
}

\author{
Bruno Freitas Valbon, Renato Ambrosio Jr, Juliana Glicéria, Rodrigo Santos, Allan Luz, Milton Ruiz Alves
}

\section{ABSTRACT}

Purpose: To report a case of post-LASIK corneal ectasia due to a thick flap, while the contralateral eye did not develop ectasia after an incomplete deep flap cut, followed by a thinner flap LASIK procedure.

Methods: Case report.

Results: This 45 years old female patient had bilateral myopic LASIK in 1999. Preoperative anterior curvature map was regular with no signs of keratoconus. Central keratometry was $42.88 \times$ $44.70 @ 163$ in OD and $43.43 \times 45.24 @ 175$ in OS. Ultrasound central corneal thickness was $586 \mu \mathrm{m}$ and $619 \mu \mathrm{m}$ in the right eye and left eye, respectively. Corneal OCT identified a deep meniscus-shaped LASIK flap, with a central thickness of a $392 \mu \mathrm{m}$ in the right eye, and an incomplete deep peripheral cut in the left eye with a thinner meniscus-shaped LASIK flap.

Conclusion: Unilateral ectasia after LASIK may occur due to a thick flap which leads to biomechanical failure of the cornea.

Keywords: Ectasia, Thick flap, Microkeratome, Tomography, Biomechanics.

How to cite this article: Valbon BF, Ambrosio R Jr, Glicéria J, Santos R, Luz A, Alves MR. Unilateral Corneal Ectasia after Bilateral LASIK: The Thick Flap Counts. Int J Kerat Ect Cor Dis 2013;2(2):79-83.

\section{Source of support: Nil}

\section{Conflict of interest: None declared}

\section{INTRODUCTION}

Corneal ectasia is a rare but very severe and widely recognized complication of laser in situ keratomileusis (LASIK). ${ }^{1}$ Although abnormal corneal topography appears to be the most important preoperative risk factor, ${ }^{2}$ progressive corneal ectasia has occurred in eyes with apparently normal topographies. ${ }^{3}$ The etiology of iatrogenic keratectasia is related to the insufficient residual corneal bed thickness, which is not capable of maintaining the biomechanical strength of the cornea following LASIK surgery. ${ }^{4}$ Underestimation of excimer laser ablation depth, error in measuring corneal thickness (i.e. discrepancy between central ant true thinnest values), and underestimation of flap thickness are recognized as possible causes for mysterious ectasia cases. ${ }^{5}$ Flap geometry, thickness, diameter, and hinge length are important characteristics that affect the biomechanical impact on the cornea. Appropriate surgical planning and controlling such characteristics will reduce the risk of ectasia. ${ }^{6}$ It has been hypothesized that thick flaps cause postoperative ectasia. ${ }^{3,5,7-10}$
We report a case of unilateral progressive corneal ectasia related to a thick flap LASIK in a patient that had bilateral LASIK, with no identifiable classical preoperative risk factors related to clinical parameters, topography and central thickness.

\section{CASE REPORT}

A 45-year-old woman was referred for a second opinion because of 'a poor result after LASIK in the right eye'. Family history was negative for ocular disorders. Patient referred LASIK procedure 13 years ago, in 1999). A chart review indicated preoperative refraction was $-5.00-0.50$ $\times 140$, giving $20 / 20$ in the right eye and $-5.00-0.50 \times 10$, giving $20 / 20$ in the left eye. Preoperative topopraphy was relatively normal, with no signs of keratoconus. Simulated keratometry was $42.88 \times 44.70 @ 163$ in the right eye and $43.43 \times 45.24 @ 175$ in the left eye. Preoperative ultrasound central corneal thickness (CCT) measurements were $586 \mu \mathrm{m}$ in the right eye and $619 \mu \mathrm{m}$ in the left eye.

In 1999, LASIK procedure with the microkeratome (nonspecified microkeratome, with $160 \mu \mathrm{m}$ plate) was attempted in both eyes. However, the procedure was aborted in the left eye because of incomplete formation of the flap. A second LASIK flap was created in left eye approximately 3 months later. No direct intraoperative measurements of the flap or residual stromal bed thickness were obtained. The patient mentioned that her uncorrected visual acuity (UCVA) improved after surgery, however she reported progressive deterioration of vision in her right eye over the four last years.

Corneal ectasia was confirmed in April 2013, 13 years after LASIK, when we first saw the patient for second opinion. UCVA was 20/800 in the right eye and 20/60 in the left eye. The best spectacle-corrected visual acuity (BSCVA) was 20/400 with $-4.25-8.00 \times 85$ in the right eye and $20 / 25$ with $+0.75-0.50 \times 165$ in the left eye. Slitlamp biomicroscopy, identified a nasal hinge LASIK flap with a relatively clear cornea, mild presence of particles on the interface which enabled the assumption of a thicker flap in OD, no striae or epithelial ingrowth was identified. Fundoscopic examination found no abnormalities in either eye. Goldmann applanation tonometry, performed at $3 \mathrm{pm}$, was $7 \mathrm{~mm} \mathrm{Hg}$ in OD and $10 \mathrm{~mm} \mathrm{Hg}$ in OS.

Retrospective calculation of the ectasia risk score system (ERSS) ${ }^{7}$ identified low risk in both eyes. Patient was 
31 years in 1999 ( 0 points), CCT was higher than $510 \mu \mathrm{m}$ in both eyes ( 0 points), topography revealed normal/symmetric bow tie in both eyes ( 0 points), manifest refraction was less myopic than $-8 \mathrm{D}$ in both eyes ( 0 points). However, while the calculated predicted residual stromal bed would be higher than $300 \mu \mathrm{m}$ in both eyes ( 0 points), the post hoc measurement with OCT identified lower RSB.

Placido-disk based topography (Oculus Keratograph 5). Pentacam HR corneal tomography (Oculus Optikgeräte $\mathrm{GmbH}$, Wetzlar, Germany) and anterior segment optical coherence tomography (OCT RTVue, Optovue, Fremont, CA, USA) were evaluated. The Ocular Response Analyzer (ORA; Reichert Ophthalmic Instruments, Depew, New York) and Corvis ST (Scheimpflug Technology, Oculus Optikgeräte $\mathrm{GmbH}$, Wetzlar, Germany) were used for biomechanical assessments in both eyes.

In the right eye, corneal curvature by Placido and Scheimpflug revealed marked inferior steepening, with keratometric values higher than $59 \mathrm{D}$, hyperprolate shape (Q-value in $6 \mathrm{~mm}=-1.08$ ) and marked asymmetry (Fig. 1A). In the left eye, curvature maps revealed an oblate (Q-value in $6 \mathrm{~mm}=0.93$ ) shape with low regular toricity and no signs of natural ectasia. Central keratometric values were $39.3 \mathrm{D}$ (a) 1.5 (K1), 41.2 D (K2), and 40.2 D (Km) in OS (Fig. 1B). The elevation maps (back) referenced to floating BFS for the $8 \mathrm{~mm}$ zone demonstrated an island pattern with $80 \mu \mathrm{m}$ in the right eye and $-4 \mu \mathrm{m}$ in the left eye (Figs $1 \mathrm{C}$ and $1 \mathrm{D}$, respectively).

The LASIK flaps were identified by high resolution, spectral domain AS-OCT imaging. In the right eye, a meniscus-shaped LASIK flap was seen with a central thickness of $392 \mu \mathrm{m}$ and RSB thickness of $117 \mu \mathrm{m}$ (Fig. 2). In the left eye, two meniscus-shaped LASIK flaps were found. One formed during the aborted attempt measured $384 \mu \mathrm{m}$ in the periphery. The other flap measured $180 \mu \mathrm{m}$ in the center, showing a central RSB thickness of $306 \mu \mathrm{m}$ (Fig. 3).

Biomechanical measurements taken by ORA were considered (Fig. 4). The corneal hysteresis $(\mathrm{CH})$ was 9.7 and $11.3 \mathrm{~mm} \mathrm{Hg}$ in the right eye and left eye, respectively. The corneal resistance factor (CRF) was $9.7 \mathrm{~mm} \mathrm{Hg}$ and

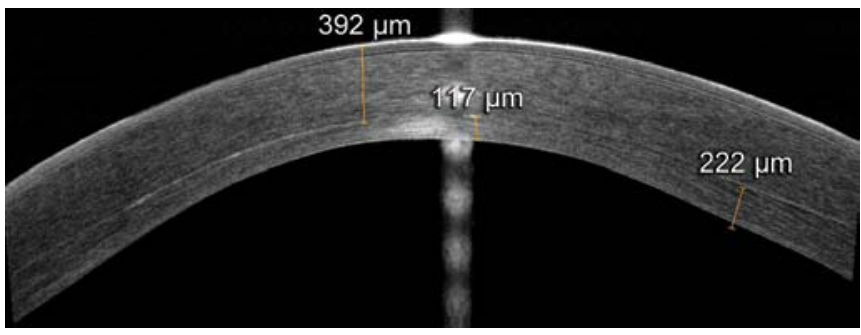

Fig. 2: Anterior segment OCT of the right eye showing a flap thickness of $394 \mu \mathrm{m}$ and a minimum residual stromal bed of $117 \mu \mathrm{m}$

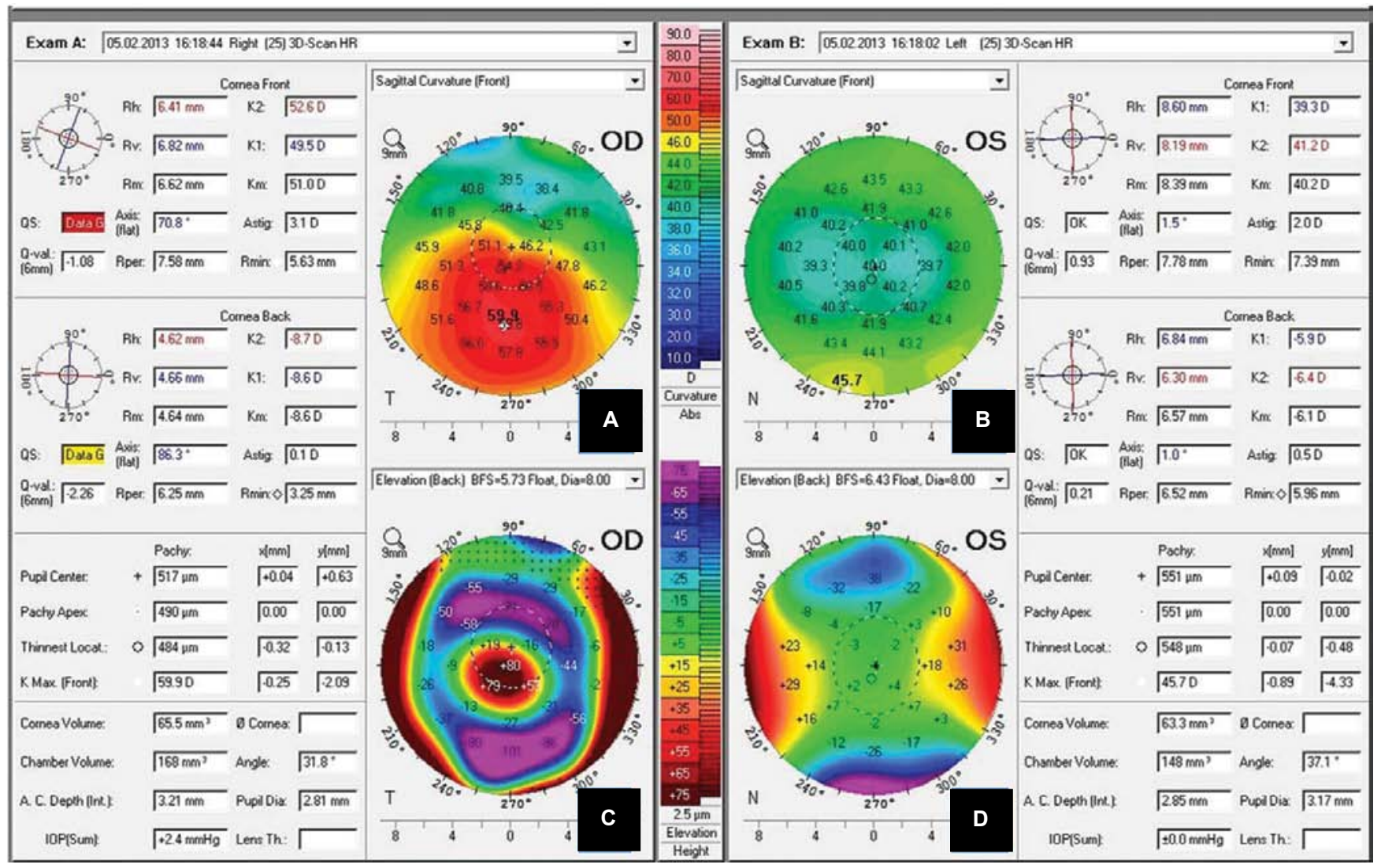

Figs 1A to D: Pentacam curvature sagittal maps. Note a pattern of ectasia with inferior steepening and keratometric values $>59.00 \mathrm{D}$ in right eye $(A)$ and the normal corneal asphericity with low toricity and observed myopic ablation profile in left eye (B). Elevation maps (back) referenced to floating BFS for the $8 \mathrm{~mm}$ zone demonstrated an island pattern with $80 \mu \mathrm{m}$ in the right eye (C) and $-4 \mu \mathrm{m}$ in the left eye (D) 


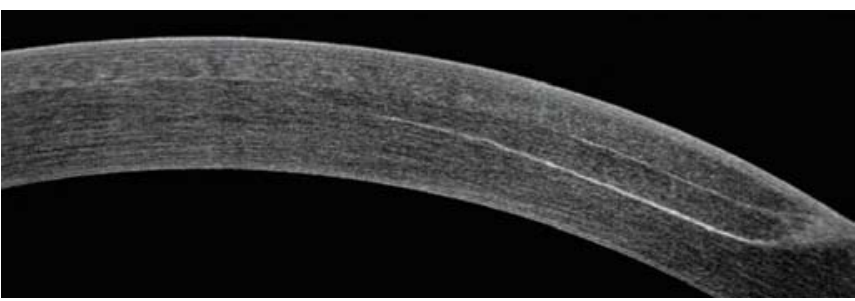

Fig. 3: Anterior segment OCT of the left eye showing a two meniscus-shaped LASIK flaps. The flap measured $180 \mu \mathrm{m}$ in the center and a central RSB thickness of $306 \mu \mathrm{m}$

$10.3 \mathrm{~mm} \mathrm{Hg}$ in the right eye and left eye, respectively. We observed that $\mathrm{CH}$ and $\mathrm{CRF}$ were lower in the right eye than in the left eye, identifying biomechanical failure in right eye. In right eye the IOPg was $14.8 \mathrm{mmHg}$ and IOPcc was 16.1 $\mathrm{mm} \mathrm{Hg}$. In left eye, the IOPg and IOPcc were $12.5 \mathrm{~mm} \mathrm{Hg}$ and $12.4 \mathrm{~mm} \mathrm{Hg}$, respectively.

The Corvis ST also was used on both eyes (Fig. 5). This device integrates ultra-high-speed Scheimpflug imaging with
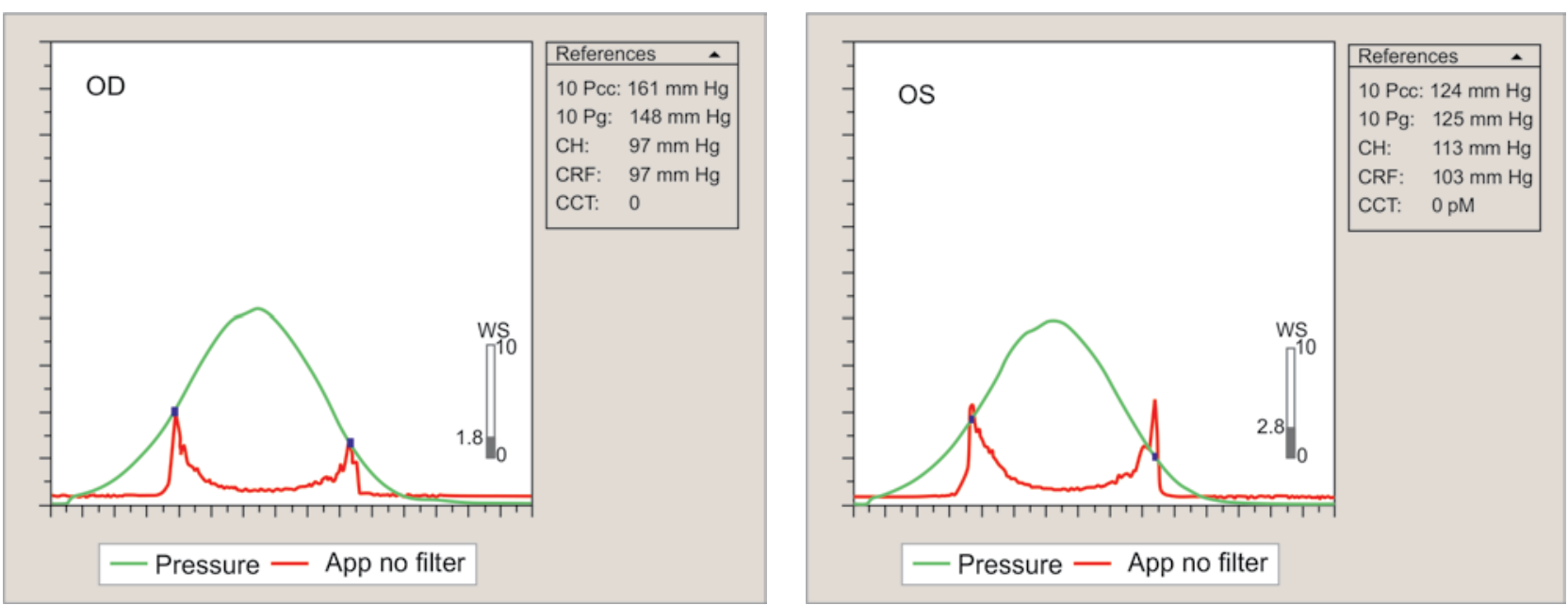

Fig. 4: ORA biocorneagram. Note that ORA signals in right eye were lower than in left eye
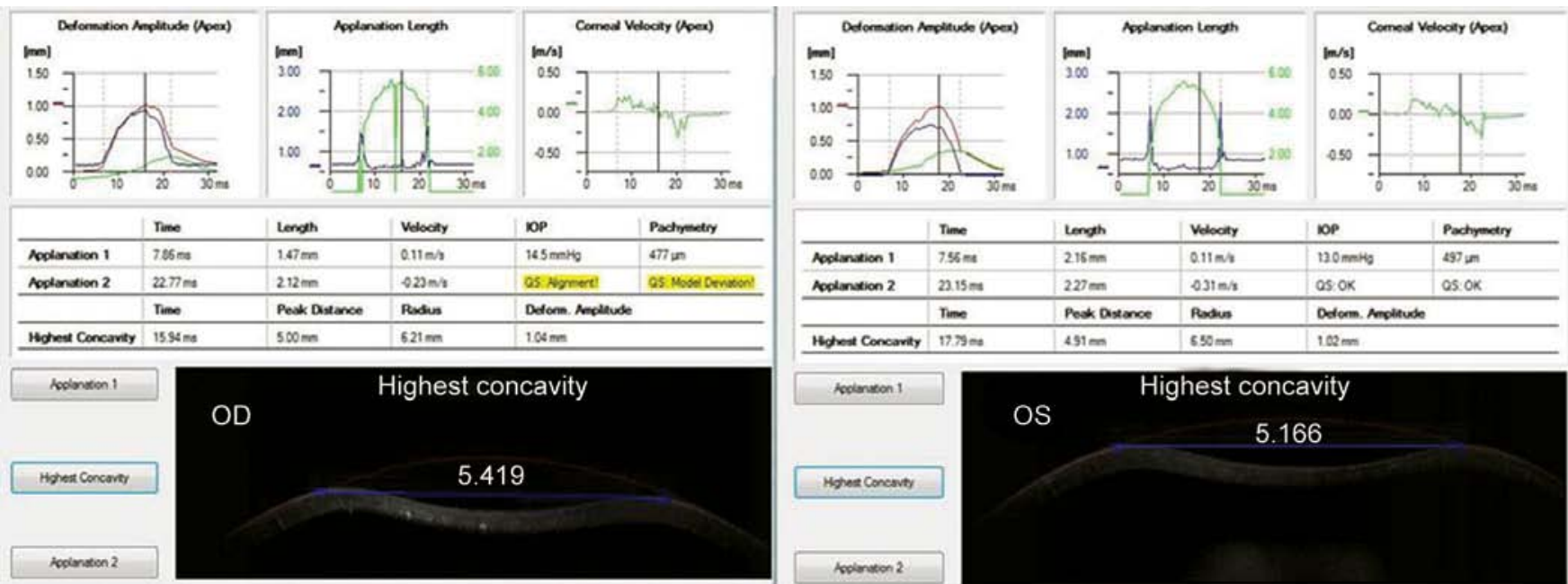

Fig. 5: The Corvis Scheimpflug technology in both eyes were measured. Note that the significant increase in deformation amplitude and of oscillation of the cornea after the air pulse in right eye is greater than that left eye 


\section{DISCUSSION}

Iatrogenic corneal ectasia is a relatively rare but sever complication after laser in situ keratomileusis. ${ }^{8}$ Possible mechanisms for post-LASIK ectasia are pre-existing corneal pathology primarily in the form of keratoconus (or form fruste of keratoconus) or chronic biomechanical failure due to inadequate residual stroma bed, which may be related to excessive ablation or excessively thick corneal flap.

Cases of ectasia have occurred in eyes with normal topographies, and Binder reports that eyes with a preoperative CCT greater than $591 \mu \mathrm{m}$ may developed ectasia. ${ }^{9}$ Pallikaris et $\mathrm{al}^{10}$ indicates this in six eyes with a residual bed thickness greater than $250 \mu \mathrm{m}$ and Comaish et $\mathrm{al}^{11}$ points to the regularity of the cut of the flap made by the microkeratome. However, the cause of the corneal ectasia after LASIK seems to be enigmatic and mysterious in some cases. Cases of corneal ectasia without risk factors should be investigated for biomechanical properties of the cornea. Irregular flaps with thicker peripheral depths could theoretically negatively affect corneal biomechanics and could be a cause for postoperative ectasia. ${ }^{3}$ Spadea et $\mathrm{al}^{5}$ reports a case of the keratectasia after thick flap $(260 \mu \mathrm{m})$ LASIK with microkeratome and concludes that the excessive flap thickness and excessive ablation produced progressive keratectasia. Giledi et al ${ }^{12}$ demonstrates that a thicker-thanexpected flap can lead to a thinner-than-anticipated residual cornea and subsequent ectasia, and showed that reports of ectasia after LASIK in normal-thickness corneas reflect thicker-than-anticipated flaps.

In this case report, we provide an example of unilateral corneal ectasia after LASIK due to a thick lamellar cut in the right eye with a low ERSS score and without preoperative risk factors. The contralateral eye did not develop corneal ectasia after a deep incomplete cut which was not lifted so that LASIK procedure was aborted. A second thinner flap was successfully created for the completion of LASIK procedure in OS. AS-OCT was utilized to identify a meniscus-flap configuration that measured $392 \mu \mathrm{m}$ and an RSB that measured $117 \mu \mathrm{m}$ in the right eye. In the left eye, the AS-OCT identified two meniscus-flap configurations, a thicker and incomplete one in the periphery and a thinner one.

This case illustrates that the flap plays a major role in the biomechanical weakening impact of LASIK. The thick flap was considered the cause of the corneal ectasia after LASIK in this case. The type of microkeratome used was not specified. However, this is known that novel microkeratomes such as the Moria OUP (Moria SA, Antony, France) enable flap creation with lower variability than older instruments, such as the M2 (Moria SA, Antony, France). ${ }^{13}$
However, the advent of femtosecond lasers definetively enhanced the accuracy, by reducing the standard deviation for flap thickness, as well as improving geometry of the lamellar cut. ${ }^{13-17}$ Every surgeon should be alert about such complication and be aware about the standard deviation of the thickness of the flap from the instrumentation he or she has available.

\section{REFERENCES}

1. Seiler T, Koufala K, Richter G. Iatrogenic keratectasia after laser in situ keratomileusis. J Refract Surg 1998;14:312-317.

2. Chan CC, Hodge C, Sutton G. External analysis of the randleman ectasia risk factor score system: a review of 36 cases of post-LASIK ectasia. Clin Experiment Ophthalmol 2010 May;38(4):335-340.

3. Randleman JB, Hebson CB, Larson PM. Flap thickness in eyes with ectasia after laser in situ keratomileusis. J Cataract Refract Surg 2012 May;38(5):752-757.

4. Ambrósio R Jr, Dawson DG, Salomão M, Guerra FP, Caiado AL, Belin MW. Corneal ectasia after LASIK despite low preoperative risk: tomographic and biomechanical findings in the unoperated, stable, fellow eye. J Refract Surg 2010 Nov;26(11):906-911.

5. Spadea L, Palmieri G, Mosca L, et al. Iatrogenic keratectasia following laser in situ keratomileusis. J Refract Surg 2002;18:475-480.

6. Pietila J, Makinen P, Suominen S, et al. Corneal flap measurements in laser in situ keratomileusis using the Moria M2 automated microkeratome. J Refract Surg 2005;21:377-385.

7. Randleman JB, Trattler WB, Stulting RD. Validation of the ectasia risk score system for preoperative laser in situ keratomileusis screening. Am J Ophthalmol 2008;145(5):813818.

8. Haw WW, Manche EE. Iatrogenic keratectasia after a deep primary keratotomy during laser in situ keratomileusis. Am J Ophthalmol 2001 Dec;132(6):920-921.

9. Binder PS. Ectasia after laser in situ keratomileusis. J Cataract Refract Surg 2003 Dec;29(12):2419-2429.

10. Pallikaris IG, Kymionis GD, Astyrakakis NI. Corneal ectasia induced by laser in situ keratomileusis. J Cataract Refract Surg 2001 Nov;27(11):1796-1802.

11. Comaish IF, Lawless MA. Progressive post-LASIK keratectasia: biomechanical instability or chronic disease process? J Cataract Refract Surg 2002 Dec;28(12):2206-2213.

12. Giledi O, Daya SM. Unexpected flap thickness in laser keratomileusis. J Cataract Refract Surg 2003 Sep;29(9):18251826.

13. Zhai CB, Tian L, Zhou YH, Zhang QW, Zhang J. Comparison of the flaps made by femtosecond laser and automated keratomes for sub-bowman keratomileusis. Chin Med J (Engl) 2013 Jul;126(13):2440-2444.

14. Zhang Y, Chen YG, Xia YJ. Comparison of corneal flap morphology using AS-OCT in LASIK with the WaveLight FS200 femtosecond laser versus a mechanical microkeratome. J Refract Surg 2013 May;29(5):320-324.

15. Kanellopoulos AJ, Asimellis G. Three-dimensional LASIK flap thickness variability: topographic central, paracentral and peripheral assessment, in flaps created by a mechanical microkeratome (M2) and two different femtosecond lasers (FS60 and FS200). Clin Ophthalmol 2013;7:675-683. 
16. Zhou Y, Zhang J, Tian L, Zhai C. Comparison of the Ziemer FEMTO LDV femtosecond laser and Moria M2 mechanical microkeratome. J Refract Surg 2012 Mar;28(3):189-194.

17. Ambrósio R Jr. A revolução dos lasers de femtossegundo na oftalmologia. Revista Brasileira de Oftalmologia 2011;70: 207-210.

\section{ABOUT THE AUTHORS}

\section{Bruno Freitas Valbon (Corresponding Author)}

Postgraduate Student, Department of Ophthalmology, University of São Paulo, Brazil, Phone: 552180137117, e-mail: valbonbruno@ig.com.br

\section{Renato Ambrosio Jr}

Founder and Research Director, Rio de Janeiro Corneal Tomography and Biomechanics Study Group - Rio de Janeiro, RJ, Brazil; Associate Professor, Department of Ophthalmology, Federal University of São Paulo, Brazil

\section{Juliana Glicéria}

Resident, Department of Ophthalmology, Hospital da Piedade (RJ); Research Associate, Rio de Janeiro Corneal Tomography and Biomechanics Study Group - Rio de Janeiro, RJ, Brazil

\section{Rodrigo Santos}

Fellow, Department of Ophthalmology, Federal University of São Paulo, Brazil

\section{Allan Luz}

Postgraduate Student, Department of Ophthalmology, Federal University of São Paulo, Brazil

\section{Milton Ruiz Alves}

Professor, Department of Ophthalmology, University of São Paulo São Paulo, Brazil 